\title{
45. Pirajá da Silva, Árbitro de uma Contenda Científica
}

\author{
Joffre Marcondes de Rezende
}

\section{SciELO Books / SciELO Livros / SciELO Libros}

REZENDE, J. M. Pirajá da Silva, Árbitro de uma Contenda Científica. In: À sombra do plátano: crônicas de história da medicina [online]. São Paulo: Editora Unifesp, 2009, pp. 371-375. História da Medicina series, vol. 2. ISBN 978-85-61673-63-5. https://doi.org/10.7476/9788561673635.0046.

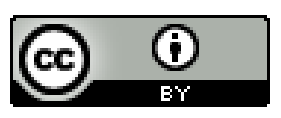

All the contents of this work, except where otherwise noted, is licensed under a Creative Commons Attribution 4.0 International license.

Todo o conteúdo deste trabalho, exceto quando houver ressalva, é publicado sob a licença Creative Commons Atribição 4.0.

Todo el contenido de esta obra, excepto donde se indique lo contrario, está bajo licencia de la licencia Creative Commons Reconocimento 4.0. 

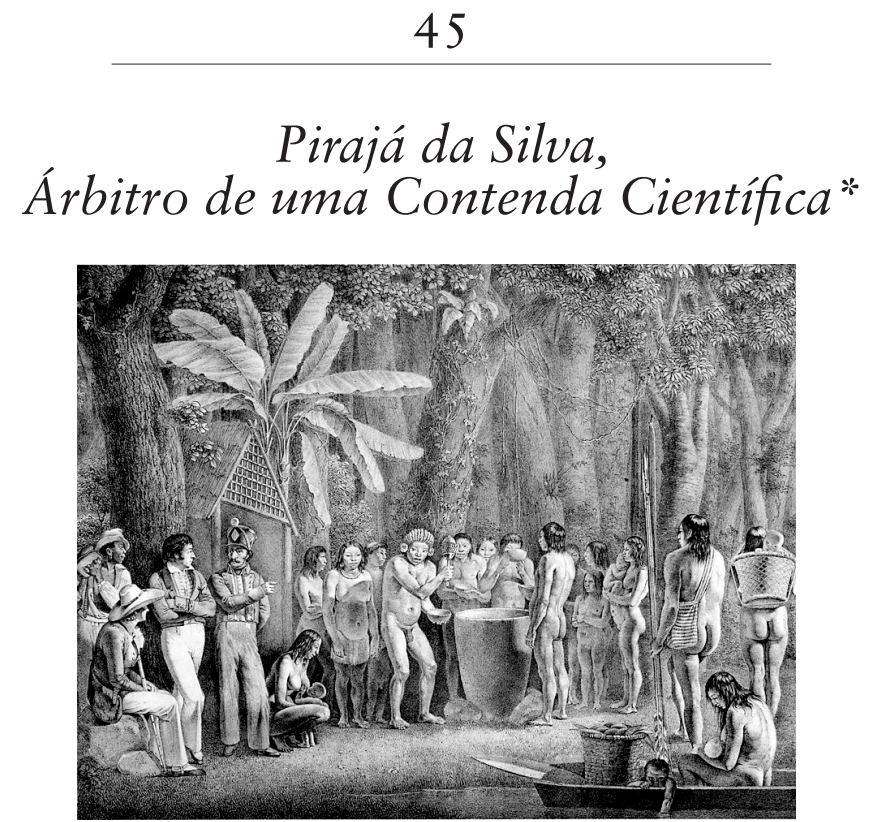

Gravura publicada na clássica obra de Von Martius, Natureza, Doenças, Medicina e Remédios dos Índios Brasileiros, traduzida por Pirajá da Silva.

Completa-se em 2008 o centenário da descoberta do Schistosoma man$\bigcup_{s o n i}$ e da esquistossomose no Brasil por Pirajá da Silva.

Manuel Augusto Pirajá da Silva nasceu em Camamu, no estado da Bahia, em I 873. Seu avô materno era um português, José Ribeiro da Silva, que acrescentou ao seu próprio nome, o topônimo indígena Pirajá, como demonstração de sua integração à nação brasileira e em homenagem às lutas que se desenrolaram na Bahia pela independência do Brasil e que culminaram com a expulsão das tropas portuguesas em 2 de julho de I 823. Pirajá é o local onde se travaram grandes combates. Deste patriarca descende a família Pirajá da Silva (Falcão, I959, pp. I-55).

Manuel Augusto Pirajá da Silva matriculou-se no curso médico da tradicional Faculdade de Medicina da Bahia, a primeira fundada por d. João vi no Brasil, tendo-se diplomado em I 896. Era dotado de inteligência invulgar e interessava-se pela cultura de modo geral, além da medicina. Paralelamente

* Modificado de Ética Revista, 6 (2), pp. 22-23, 2008. 
aos seus afazeres, estudava alemão e violino, tendo como ídolos inspiradores Goethe e Paganini.

Como outros ilustres personagens da medicina brasileira, iniciou suas atividades médicas como clínico, inicialmente em Amargosa, no estado da Bahia e, a seguir, atraído pelo desenvolvimento da Amazônia, em Manaus, onde, entretanto, permaneceu apenas por três meses, retornando a Salvador. Em 1902 foi nomeado professor assistente da primeira cadeira de Clínica Médica da Faculdade de Medicina, sediada no antigo Hospital Santa Isabel.

$\mathrm{Na}$ época pós-pasteuriana de efervescência do interesse pelas doenças infecciosas e parasitárias, em que sucessivas descobertas estavam sendo feitas, Pirajá da Silva sentiu-se atraído para investigar a patologia autóctone nessa área. No Hospital Santa Isabel dispunha apenas de um microscópio monocular e de escasso material para preparações histológicas.

Data de 1907 sua primeira contribuição, que consistiu no achado e descrição em cortes histológicas de um cancro sifilítico, do Treponema pallidum, descoberto em I905 por Schaudinn.

Dada a pobreza de seu laboratório decidiu realizar exames de fezes rotineiramente em todos os doentes internados para estudar as parasitoses intestinais. Além de ovos e larvas de parasitos já conhecidos, teve a surpresa de encontrar ovos de um verme não identificado, dotados de um espículo lateral. Revendo a bibliografia sobre o assunto, concluiu que se tratava de um helminto do gênero Schistosoma.

A esquistossomose já era de longa data conhecida na África, especialmente no Egito, porém o helminto responsável só foi descoberto em I 85 I, por Bilharz, razão pela qual, a partir daí, recebeu a denominação paralela de bilharziose.

A característica clínica mais importante na esquistossomose africana é a hematúria e a presença de ovos do verme na urina. Tais ovos são providos de um espículo de implantação terminal. Bilharz também observou, em alguns doentes hematúricos esquistossomóticos, a presença de ovos nas fezes com espículo lateral, semelhantes aos encontrados por Pirajá da Silva.

Em face desses achados, surgiu uma grande controvérsia entre duas escolas de parasitologia, lideradas por dois expoentes da parasitologia mundial: Patrick Manson, na Inglaterra, que admitia a existência de outra espécie de 
Schistosoma para explicar os ovos com espículo lateral; e Arthur Loos, de nacionalidade alemã, professor da Faculdade de Medicina do Cairo, que não valorizava a variação morfológica dos ovos e defendia uma única espécie de Schistosoma. Antecipando-se à elucidação dos fatos, Sambon, em I907, propôs a denominação de Schistosoma mansoni para a provável segunda espécie com ovos de espículo lateral.

Pirajá da Silva foi o árbitro desta contenda científica. Coube-lhe dirimir a controvérsia e confirmar a existência de uma segunda espécie, a que chamou inicialmente de Schistomum americanum e, posteriormente, de acordo com as normas de prioridade que regem a nomenclatura científica, de Schistosoma mansoni.

Em uma série de pesquisas notáveis, Pirajá da Silva obteve em casos autopsiados o verme vivo no interior da veias do sistema porta e pôde estudar-lhe a anatomia e a biologia. Encontrou vermes machos e fêmeas isolados e dois pares acasalados, estando a fêmea no canal ginecóforo do macho. Divulgou seus achados em três artigos publicados na revista Brazil-Médico, nas edições de $\mathrm{I}^{\mathrm{o}}$ de agosto, $\mathrm{I}^{\mathrm{o}}$ e 8 de dezembro de $\mathrm{I} 908$.

Seus trabalhos não tiveram, de imediato, a repercussão que mereciam. Além da atitude preconceituosa em relação aos países sul-americanos, sem tradição de pesquisa, tratava-se de um médico desconhecido dos meios científicos (Bacellar, I963, pp. 8I-88).

Em novembro de 1908 decidiu viajar a Europa para aprimorar seus conhecimentos e entrar em contato com os grandes centros de pesquisa das doenças tropicais, visando o intercâmbio científico e a divulgação de sua descoberta. Em Paris foi recebido por Blanchard, professor de parasitologia da Faculdade de Medicina de Paris, que o encaminhou a Letulle, um estudioso da esquistossomose, que reviu seu vasto material fotográfico e histopatológico. Deste contato resultou a publicação nos Archives de Parasitologie de sua monografia intitulada La Schistosomose à Bahia, em março de 1909 (Pirajá da Silva, I908/1909, pp. 283-302). Uma versão em inglês foi publicada em junho do mesmo ano no The Journal of Tropical Medicine and Hygiene (Pirajá da Silva, I909, pp. I 59-I64).

De Paris, Pirajá da Silva foi para Hamburgo, onde estagiou no Instituto de Medicina Tropical e fez amizade com Henrique da Rocha Lima, pesquisador brasileiro do Instituto Oswaldo Cruz, que lá trabalhava. 
Em I9 Io retornou à Bahia e em I9I I foi nomeado pelo presidente da República, professor de História Natural Médica da Faculdade de Medicina da Bahia. Entusiasmado com a descoberta da tripanossomíase por Carlos Chagas investigou a ocorrência da doença de Chagas e de barbeiros infectados nos arredores de Salvador. Interessou-se igualmente pela amebíase intestinal e pela miiase.

Ao final de I9 I realizou sua segunda viagem à Europa. Convidado a proferir uma conferência perante a Sociedade Alemã de Medicina Tropical em abril de ı9ı 2, falou em alemão. Refutou a escola unicista de Loos, demonstrando que se tratava de duas espécies diferentes de Schistosoma e de duas doenças distintas: a esquistossomose do Egito e a esquistossomose do Brasil. Voltando à Bahia, completou suas pesquisas sobre a esquistossomose com a descrição da cercária como um elo na complexa biologia do Schistosoma. Voltaria a escrever sobre a esquistossomose somente em I9I 6 em um número comemorativo do $50^{\circ}$ aniversário da Gazeta Médica da Bahia, no qual reuniu os trabalhos anteriores sob o título "Schistosomiasis na Bahia".

Como chefe de departamento e professor era austero, porém respeitado e estimado por seus discípulos, nos quais procurava despertar interesse pelas doenças e endemias que infelicitam o nosso povo.

Deve-se a Pirajá da Silva a tradução para a língua portuguesa da clássica obra do naturalista alemão Von Martius, Das Natureli die Kankheiten, das Arzthum und die Heilmittel der Urbewhner Brasiliens (Natureza, Doenças, Medicina e Remédios dos Índios Brasileiros).

Em vida Pirajá da Silva teve o reconhecimento do valor de sua contribuição científica em várias oportunidades. Em I9 I I foi agraciado com a medalha de ouro do Instituto de Medicina Colonial da França; em I954, o Instituto de Medicina Tropical de Hamburgo concedeu-lhe a medalha Nocht, a mais alta distinção daquela instituição, só conferida a personalidades que se destacaram por relevantes contribuições à medicina tropical. $\mathrm{O}$ governo brasileiro, em 1956, o homenageou com a Gran Cruz da Ordem Nacional do Mérito Médico. Em 1957 recebeu o título de doutor honoris causa da Universidade de São Paulo.

O cinquentenário de sua descoberta, em I958, foi condignamente comemorado, graças sobretudo à iniciativa de Edgard de Cerqueira Falcão, 
médico, escritor, historiador e ex-discípulo de Pirajá da Silva. Além das sessões comemorativas em São Paulo e em Salvador, foi criada pelo Ministro da Saúde, prof. Mário Pinotti, a medalha Pirajá da Silva e lançado, em I959, pelos Correios e Telégrafos, um selo comemorativo com a efígie de Pirajá da Silva.

Sua trajetória encerrou-se em I961, aos 88 anos, quando faleceu em sua residência em São Paulo, deixando viúva sua dedicada esposa, d. Elisa, e seus dois filhos, Paulo e Regina Pirajá da Silva.

A vida e a obra de Pirajá da Silva foram magnificamente retratadas por Edgar de Cerqueira Falcão no livro citado nas referências deste texto.

A Faculdade de Medicina da Universidade Federal da Bahia incluiu a comemoração do centenário de sua descoberta na programação dos festejos do bicentenário daquela faculdade, a primeira do país, fundada por d. João VI em I 808 .

\section{Referências Bibliográficas}

Bacellar, R. C. Brazil's Contribution to Tropical Medicine and Malaria. Rio de Janeiro, Gráfica Olímpica Editora, I963.

Falcão, E. C. Pirajá da Silva: O Incontestável Descobridor do Schistosoma mansoni.

São Paulo, Revista dos Tribunais, I959.

Pirajá da Silva, M. A. "La Schistosomose à Bahia”. Archives de Parasitology, I3, pp. 283-302, I908/I909.

. "Contribution to the Study of Schistosomiasis in Bahia". Journal of Tropical

Medicine and Hygiene, I I, pp. I 59-I64, I909. 
